\title{
HIV infections and AIDS-related deaths falling globally
}

$\mathrm{H}$ IV infections and AIDSrelated deaths have fallen around the world, thanks to more affordable antiretroviral drugs and increased HIV testing, according to a report from the Joint United Nations Programme on HIV/AIDS (UNAIDS).

New HIV infections among adults and children fell to 2.3 million in 2012, down $33 \%$ from 3.4 million in 2001 . New HIV infections among children alone dropped to 260000 in 2012, down from 550000 in 2001, a $52 \%$ reduction, the report says. AIDS-related deaths have also fallen, by $30 \%$ to 1.6 million since their peak of 2.3 million in 2005.

As of last year, 9.7 million people living with HIV had access to antiretroviral drugs in low- and middle-income countries around the world, which equates to $34 \%$ of those eligible for treatment under the World Health Organization's 2013 guidelines. Tuberculosis remains the leading cause of death for people living with HIV.

Experts working in HIV/AIDS treatment in Canada celebrated the declines the report documents, marvelling that at the height of the HIV/AIDS epidemic, they would not have imagined these gains.

"We are delighted and thrilled to see the latest report from UNAIDS. There is reason to believe we are changing the course of the epidemic," says Dr. Julio Montaner, director of the British Columbia Centre for Excellence in HIV/AIDS in Vancouver.

This sentiment is echoed by Maxine Davis, executive director of the Dr. Peter AIDS Foundation in Vancouver, who began working in the field 17 years ago. "It was hard back then to envision a day when we would be at this moment, when we see such a dialling down of the epidemic globally, even in developing countries," says Davis.

But as the global AIDS report indicates, Davis cautioned, there remain pockets of the world where new HIV

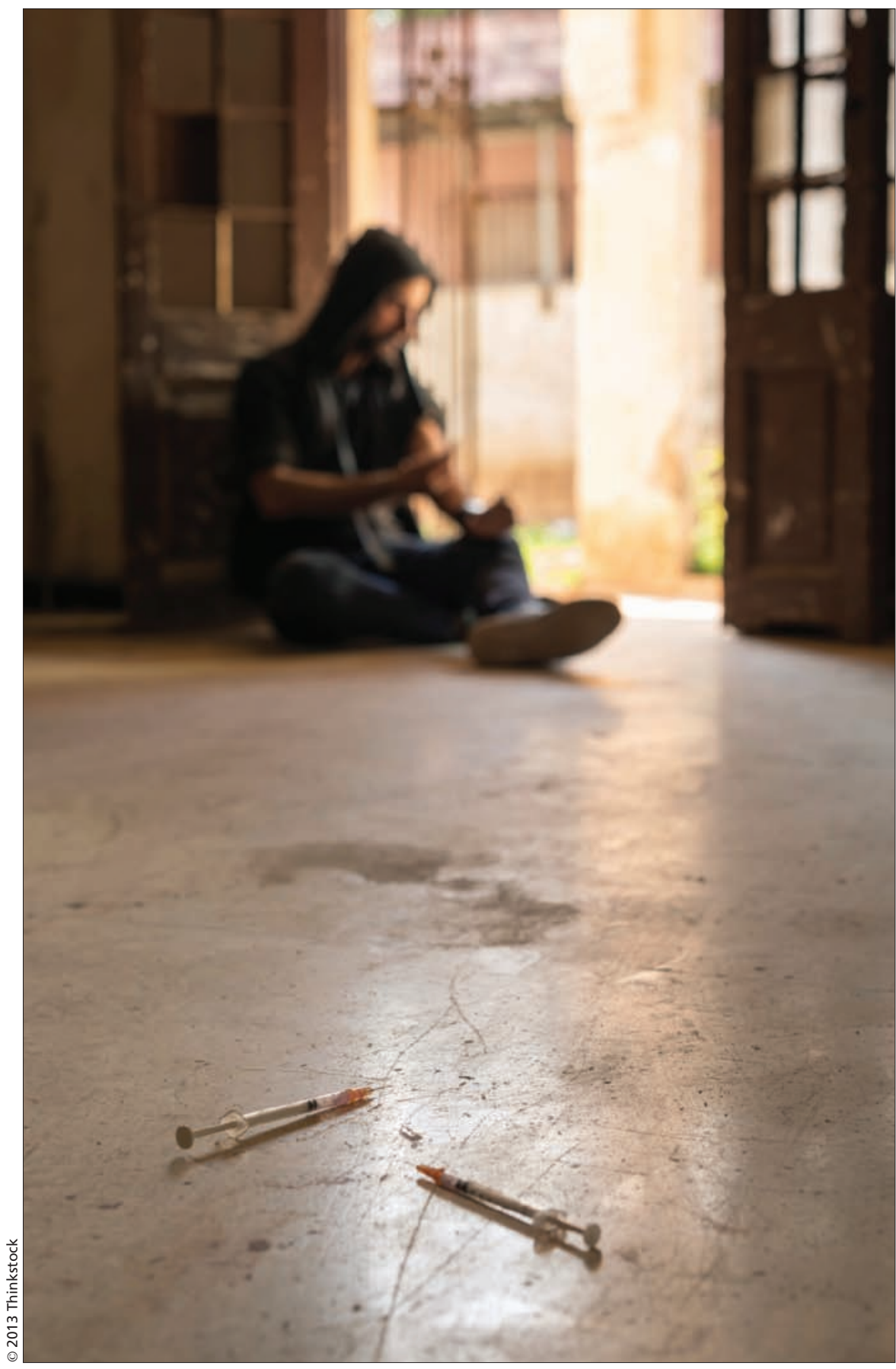

British Columbia has reduced new HIV infections by targeting high-risk populations such as injection drug users and providing them with a safe injection site and needle exchanges.

infections are on the rise, including areas in Eastern Europe, Asia and parts of Canada - particularly in places where "there is a refusal to address health care for injection drug users."
A critical part of the reason new infections are declining globally is that people consistently taking their HIV treatment are at minimal risk of transmitting HIV, Davis says. In British 
Columbia, the province's success in reducing infections among high-risk populations comes from having a safe injection site, needle exchanges, getting people on antiretroviral medication and engaging them in treatment through having a supportive, nonjudgmental clinical approach, Davis says - a system known as "cascade of care."

"From my perspective, a compelling case is needed for having that combination of service in every part of our country where there are injection drug users, a vulnerable population, so that individuals who are HIV-positive can actually get the HIV treatment they need for their own health," she added. That care should include access to a supervised injection site, Davis stressed.

Although the UNAIDS report heralds "historic declines" in new infections and deaths, as well as "the mobilization of unprecedented financing for HIV-related activities in low- and middle-income countries," the executive director of UNAIDS warns that there are signs of stagnation in global efforts to make progress toward the goal of zero new HIV infections, zero discrimination and zero AIDS-related deaths.

"The challenges are real, and they must be taken seriously if countries are to achieve their AIDS targets," Michel Sidibé warns in the foreword to the report.
Several sub-Saharan African countries are detecting decreases in condom use and/or increases in the number of people's sexual partners, both practices that increase transmission of HIV. The prevalence of HIV among injection drug users remains high around the world.

Mobilizing the money to extend antiretroviral treatment to all those who need it and to expand prevention and treatment programs is still a major challenge, Sidibé states. "Our ability to lay the foundation for an end to the AIDS epidemic continues to be undermined by a major resource gap. - Laura Eggertson, CMAJ

CMAJ 2013. DOI:10.1503/cmaj.109-4621 